\title{
CORREGIDORES Y ALCALDES MAYORES EN CATALUÑA: ¿DEL ABSOLUTISMO AL ABSOLUTISMO? (1820-1825)
}

\section{CORREGIDORES AND ALCALDES MAYORES IN CATALONIA: FROM ABSOLUTISM TO ABSOLUTISM? (1820-1825)}

\author{
Manuel Santirso Rodríguez \\ Universitat Autónoma de Barcelona
}

SUMARIO: I. INTRODUCCIÓN. II. INTERINIDAD (1820). III. IMPLANTACIÓN (1821). IV. DESPLIEGUE (1821-1822). V. REVOCACIÓN (1823). VI. ALGUNAS CONCLUSIONES.

Resumen: Los liberales que llegaron al poder en 1820 quisieron hacer realidad el sistema administrativo previsto por las Cortes de Cádiz uno años antes, pero el intento quedó frustrado por la imprevisión, la falta de medio y la contrarrevolución realista. La segunda restauración de 1823 depuró esa nueva administración y pretendió volver al pasado, pero pronto quedó claro que ese retroceso tampoco era posible.

Abstract: The liberals who came to power in 1820 wanted to put into operation the administrative system envisaged by the Cortes of Cadiz a few years earlier, but this attempt was frustrated by the lack of foresight and means and by the royalist counterrevolution. Second restoration of 1823 purified this administration and tried to go back to the past, but that setback was not possible either.

Palabras clave: Corregidores, Alcaldes mayores, Historia de Cataluña, Historia de España, Trienio constitucional, Restauración absolutista.

Key Words: Corregidores, Alcaldes mayores, History of Catalonia, History of Spain, Cosntitutional Triennium, Absolutist Restoration.

\section{INTRODUCCIÓN}

Conocemos bien la estructura y el espíritu de la administración territorial en Cataluña desde la Nueva Planta de 1716, hay cumplida noticia de quienes la hicieron funcionar el siglo siguiente, se ha explicado con qué criterios se les nombró y de qué modo se fueron relevando en su cometido. No obstante, las investigaciones sobre ese nivel del poder regio se detienen ante la barrera cronológica e historiográfica del año 1808 y dejan en penumbra el tramo final, 
hasta 1833-18341. Hay valiosos estudios de Historia del Derecho sobre el breve paréntesis constitucional del Trienio 1820-1823, pero también cierta desconexión entre ellos y la Historia, sobre todo politica, del periodo, que asimismo cuenta con brillantes aportaciones ${ }^{2}$. Además, la primera disciplina prefiere relatar los cambios efectuados sobre un continuo esencial, mientras que la segunda privilegia las rupturas.

Este artículo busca colmar en lo posible ese hueco metodológico y conceptual. Los liberales del Trienio se esforzaron por instaurar la planta administrativa prevista en Cádiz - por una parte- y por dar cauce a las libertades -por otra-, pero siempre a partir de los principios de igualdad ante la ley y de racionalidad del aparato del Estado. Lo primero les llevó a eliminar las bailías señoriales y a convertir a sus titulares en delegados regios, de acuerdo con el decreto de abolición de señorios jurisdiccionales de 6 de agosto de 1811. E1 segundo criterio les condujo a desarrollar la Instrucción para el gobierno económico-politico de las provincias de 23 junio de 1813 y a trazar un nuevo mapa militar. Así quedaron claramente separadas las funciones judicial y castrense, ejercidas por funcionarios estatales especializados $y$ no elegidos, $y$ la administrativa, confiada a las instituciones representativas de ayuntamientos y diputaciones provinciales ${ }^{3}$. Era un esquema elegante y no muy distinto del actual, pero los acontecimientos de 1820-1823 dificultaron su implantación e impidieron su continuidad.

Cataluña aparece como uno de los mejores lugares para estudiar ese intento, de entrada porque las nuevas instituciones apenas habian arraigado en el primer periodo constitucional de 1812-1814. Fue el último reducto del ejército napoleónico, y en la parte que retuvo el bando patriota no se instalaron juzgados de primera instancia, no se aplicó ningún proyecto de división provincial y los primeros jefes politicos fueron los capitanes generales. En resumen, poco quedaba por desmantelar cuando Fernando VII firmó el decreto de 7 de mayo de 1814 que anulaba la legislación de Cádiz ${ }^{4}$. Las cosas parecian haber vuelto casi

*. Este artículo se enmarca en el proyecto de investigación ESNACAT, "España y nación en Cataluña" (HAR2015-67173-P), con financiación de MINECO/FEDER, UE.

1. Rafael Cerro Nargánez da una lista hasta 1834 en "La nómina de los alcaldes mayores de Cataluña (1717-1834)" (Ius Fugit, n ${ }^{\circ}$ 8-9, 1999-2000), pero el estudio de sus integrantes se detiene en 1808. Se encontrará una base para esa lista en ARCHIVO DE LA CORONA ARAGÓN, REAL AUDIENCIA -en adelante, ACA-RA-, reg. 1.685. "Índice de los alcaldes mayores de Cataluña" (relación alfabética y cronológica).

2. Para lo primero, hablo de Ricardo Gómez Rivero, Los jueces del Trienio liberal, Ministerio de Justicia, Madrid, 2006, o de Regina Polo, "El régimen local entre el absolutismo y el liberalismo (la organización municipal y territorial de Salamanca, 1814-1833”, Anuario de Historia del Derecho Español, vol. LXXXI, 2011. Para lo segundo, se trata de síntesis como Ramón Arnabat, Visca el Rei i la religió! La primera guerra civil de la Catalunya contemporània (1820-1823), Pagès editors, Lleida, 2001, y nuevas aportaciones, como Jordi Roca, "Política, liberalisme i revolució a Barcelona, 1820-1823”, tesis doctoral, Universitat Autònoma de Barcelona, 2007.

3. Ver Joaquín Varela Suanzes-Carpegna, "Las Cortes de Cádiz y la Constitución de 1812 (una visión de conjunto)", Corts. Anuario de Derecho Parlamentario, $\left.\mathrm{n}^{\circ} 26,2012\right)$, pp. 200-202.

4. Para esa fase anterior, véase Autor, "La administración territorial de Cataluña durante la Guerra Peninsular y las Cortes de Cádiz, 1808-1814”, Instituto Jerónimo Zurita, n. 93 (2019), en prensa. 
al estado previo a la guerra, más aún que en otras provincias de la monarquía, pero apenas seis años más tarde...

\section{INTERINIDAD (1820)}

El día de San José de 1820, muy poco después de que Fernando VII mintiese que marcharía por la senda constitucional, el brigadier Josef de Castellar era nombrado jefe político de Cataluña y presidente de su Diputación Provincial restaurada, cargos que mantendría también con la nueva Diputación surgida de las elecciones provinciales de mayo ${ }^{5}$. El 14 de marzo anterior, un decreto había confirmado como jueces de primera instancia interinos a los corregidores $\mathrm{y}$ alcaldes mayores o tenientes de corregidor que jurasen la Constitución ${ }^{6}$. Los jueces perderían "todo poder gubernativo" más adelante, cuando se instalaran los nuevos ayuntamientos constitucionales y se consumase la disociación entre poder ejecutivo y judicial. Por otra parte, el decreto de abolición de señoríos jurisdiccionales fue ratificado el 13 de abril de 1820 para erradicar los vestigios feudales que hubieran permanecido por falta de desarrollo o por sentencias contrarias.

En Cataluña, el cargo de corregidor se mantuvo de entrada, porque la división provincial que debía eliminarlo no se había fijado aún, pero sobre todo porque tenía un carácter exclusivamente castrense, de espada y no de letra, que llevaba consigo el gobierno militar y politico de distritos y plazas. Así las cosas, tenía lógica que también fueran militares los jefes politicos que debian mandar a los corregidores, al menos mientras permaneciera ese doble cometido ${ }^{7}$. Por otra parte, la equiparación de las alcaldias mayores con los juzgados de primera instancia y de los corregimientos con los gobiernos militares facilitaba la separación de funciones que perseguía el nuevo orden.

En vísperas de la restauración constitucional, estos eran:

5. Castellar juró el 31 de marzo 1820 y cesó en 5 de diciembre; había sido nombrado para el mismo cargo en Valencia, en permuta con José María Gutiérrez de Terán (la ejecutoria del primero, en Manel Risques Corbella, El Govern civil de Barcelona el segle XIX, Publicacions de l'Abadia de Montserrat, Barcelona, 1995, pp. 184-205). Terán solo permaneció en Cataluña entre el 23 de diciembre de 1820 y el 20 de febrero de 1821, cuando murió; Castellar volvería a Barcelona en 1822, pero como gobernador militar (nombrado el 20 de marzo, ACA-RA, reg. 1.420, fol. 81).

6. Ricardo Gómez Rivero, Los jueces del Trienio liberal, op. cit., pp. 74 y 141. En esas circunstancias, poco impacto podía tener el Decreto de 19 de abril de 1820 de reposición de separados por ideas constitucionales en 1814 .

7. La probable extinción del cargo llevó a que algunos, como el corregidor Perol de Manresa y el gobernador Gispert de Aran, pidieran en julio de 1820 certificaciones de su ejercicio en los años previos (ACA-RA, reg. 1.418, 155 y 172). 
Tabla 1: Corregidores de Cataluña a inicios de $1820^{8}$

\begin{tabular}{lllc}
\hline \multicolumn{1}{c}{ CORREGIMIENTO } & EMPLEO & \multicolumn{1}{c}{ NOMBRE } & ENTRA \\
\hline VIC & Tte. col. & Cesáreo Escobar & 1814 \\
VALLE DE ARAN & Coronel & Antonio Gispert & 1814 \\
MANRESA & Coronel & José Perol & 1814 \\
PUIGCERDÀ & Coronel & Nicolás Dusmet & 1815 \\
TALARN & Coronel & Juan Antonio de Prat & 1819 \\
VILAFRANCA PENEDĖS S & Coronel & José de Olzinellas & 1815 \\
CERVERA & Brigadier & Guillermo Nash & 1815 \\
MATARÓ & Brigadier & Barón de la Barre (int. J. J. & 1814 \\
& & Muñoz) & \\
FIGUERES & Mcal. campo Joaquín Caamaño Pardo & 1815 \\
LLEIDA & Mcal. campo José Bellido & 1819 \\
TARRAGONA & Mcal. campo Marqués de Zambrano & 1819 \\
TORTOSA & Mcal. campo Antonio García Conde & 1815 \\
BARCELONA & Tte. gral. & Francisco de Copons & 1817 \\
GIRONA & Tte. gral. & Juan José García de Velasco & 1814 \\
\hline
\end{tabular}

El aumento de empleo militar medio registrado respecto a 1815 y 1808 parece indicar que ya no se trataba de cómodos retiros para veteranos, aunque una parte se produjo por ascenso en el mismo puesto ${ }^{9}$.

La secuencia de pronunciamientos y formación de juntas, típica de la revolución española, modificó este cuadro en marzo de 1820, aunque sin la violencia de $1808^{10}$. Ningún corregidor cayó muerto esta vez a manos de los alzados, que se contentaron con unos cuantos ceses: el de Copons en Barcelona, reemplazado por el mariscal de campo Joaquín Ruiz de Porras; el de García de Velasco en Girona, sustituido por el brigadier Guillermo Minali; el del marqués de Zambrano en Tarragona, en cuyo lugar entró el brigadier Miguel de Sarachaga, y el del corregidor interino de Mataró, Ruiz de la Torre, a quien "con arreglo a la Constitución no le correspondía tener el mando militar, y [se] le ha obligado a

8. Estado militar de España. Año de 1820, Imp. Real, Madrid, 1820, pp. 144-145. La publicación no contempla el relevo en Tarragona entre el conde de España y el marqués de Zambrano, verificado de 1819, que sí consta en ACA-RA, reg. 1.417, 227 y 229, y en ARCHIVO HISTÓRICO NACIONAL, Consejos -en adelante, AHN, Consejos-, leg. 18.553. En Mataró, el barón de la Barre llevaba desde mayo de 1817 reemplazado interinamente por el coronel José Muñoz de la Torre (ACA-RA, reg. 1.415, 207, y AHN, Consejos, leg. 18.545).

9. Si se puntúan los empleos en una escala de 1 para teniente coronel y 5 para teniente general, en 1808 sumarian 36 puntos (sin ningún teniente general); en 1815, 40, y en 1820, 43 (Estado militar de España. Año 1808, Imprenta Real, Madrid, 1808, pp. 116-119, y Estado militar de Cataluña. Año de 1815, Imp. de Agustín Roca, Barcelona, 1815, pp. 10-11). Sobre la cotización del puesto en el escalafón en el siglo XVIII, Josep Maria Gay Escoda, El corregidor a Catalunya, Madrid: Marcial Pons, 1997, p. 713, y María del Carmen Irles Vicente "Los extranjeros en la administración corregimental española del siglo XVIIP”, en M. B. Villar García y P. Pezzi Cristóbal (eds.), Los extranjeros en la España moderna. Actas del I Coloquio internacional celebrado en Málaga del 28 al 30 de noviembre de 2002, s. e., Málaga, 2003, p. 443.

10. Autor, "La administración territorial de Cataluña...", op. cit. 
separarse de él"11. El capitán general Pedro Villacampa destituyó al gobernador de Figueres, Caamaño, quien no aceptó su cese y pasó a cuartel hasta que ocupó su puesto el mariscal de campo Manuel Pueyo ${ }^{12}$. Al de Tortosa, García Conde, no le sirvió de mucho su profesión de constitucionalismo, pues sería reemplazado por el mariscal de campo Miguel de Haro a mediados de diciembre ${ }^{13}$. Tan solo el gobierno militar de Lleida mantuvo a su titular; los de Manresa, Cervera y Talarn también permanecieron, pero como meros comandantes de armas, cargo que también tuvieron desde una fecha imprecisa Francisco Palou en Vic, José Ibarra en Vilafranca del Penedès, José Escudero en Puigcerdà y Pedro Payre en el Valle de Aran ${ }^{14}$. Es aún más difícil saber cuándo entró en funciones Juan Seró en Mataró, pero está claro que el nuevo elenco se mantendría en 1821 y $1822^{15}$.

La renovación de las alcaldias mayores tras la guerra y el retorno al absolutismo se había completado en 1816, y en los tres años siguientes se produjeron solo seis relevos, uno de ellos por traslado de una alcaldia a otra ${ }^{16}$. A inicios de 1820, se había reducido aún más la proporción de catalanes, que había alcanzado sus cotas máximas durante la guerra: en 1820 ya lo eran solo 6 sobre

11. Parte del capitán general de Cataluña, Pedro Villacampa, al secretario de Estado de Guerra, de 13 de marzo de 1820, transcrito en marqués de Miraflores [Manuel Pando Fernández de Pinedo], Documentos a los que se hace referencia en los apuntes histórico criticos sobre la Revolución de España, Londres, Oficina de Ricardo Taylor, Londres, vol. I, p. 78. También fueron expulsados del mando en Barcelona los gobernadores de la Ciudadela y Montjuïc, Pedro de Grimarest y Juan Desvalls, y en Tarragona, el teniente de Rey, Francisco Dalmau. Zambrano "fue detenido por sus soldados en marzo de 1820, al triunfar la revolución liberal y no querer jurar la constitución" (Juan A. Sandoval, anexo a "La defensa de Tarifa durante la Guerra de la Independencia", Al-Qantir, $\mathrm{n}^{\circ}$ 13, 2012, pp. 272-274); no obstante, en 1821 sería nombrado vocal de la Junta Consultiva del Ministerio de la Guerra y, como se sabe, representaría un importante papel como secretario de Guerra desde 1825 a 1832.

12. Diccionario Biográfico de la RAH, versión on line, "Caamaño Pardo, Joaquin", <http:/ / dbe.rah.es/biografias / 84809/joaquin-caamano-pardo> (consultada en 6-1-2019).

13. Joan Ramon Vinaixa i Miró, El Trienni constitucional al partir de Tortosa (1820-1823). Aproximació histórica, Cossetània, Valls, 2003, p. 29, y Gazeta del Gobierno, n. 171, 17-12-1820. Tanto Haro como Ruiz de Porras eran inequivocamente liberales.

14. El Estado militar de España. Año de 1821 (Imp. Nacional, Madrid, 1821, pp. 131-133) no incluye una relación de esas comandancias y da los gobiernos de Puigcerdà y Aran como vacantes, así que se ha usado la reconstrucción de Ramon Arnabat en "Revolució i contrarevolució a Catalunya durant el Trienni liberal (1820-1823)", tesis doctoral, UPF, 1999, p. 1.879). Con todo, Olzinellas seguía al mando en octubre de 1820 (p. 324).

15. Antoni Martí i Coll, "Els inicis a Mataró de l'ominosa década (memòries d'un regidor degà)", Sessió d'estudis mataronins, $\mathrm{n}^{\circ}$ 24, 2007, p. 162. El Diccionario biográfico de la RAH, versión on line, indica como fecha de muerte de Minali 1820, pero también recoge la concesión de la cruz San Fernando de $3^{\mathrm{a}}$ clase en 1822 ("Minali, Guillermo", <http://dbe.rah.es/biografias/52813/guillermo-minali>, consultada en 6-1-2019), lo que resulta más congruente con el Estado militar de España. Año de 1822, s.e., Madrid, 1822, p. 122.

16. Solo uno, el verificado en Igualada, parece haberse debido a fin de mandato sexenal; la vacante de Barcelona se derivó del asunto de Dalmau, mientras que las de Girona, CamprodonOlot y Tortosa se produjeron por defunción de sus anteriores titulares (ACA-RA, reg. 1.415, 449 y 470, y reg. 1.417, 32). 
21 (29\%), los mismos que en 1808, frente a los 8 de 1816 (38\%) ${ }^{17}$. En conjunto, los alcaldes mayores convertidos en jueces eran veteranos (con una edad promedio de 51 años) que no habían alcanzado los mayores grados académicos (solo eran doctores López Blanco y Olóriz), pero acreditaban mucha experiencia previa: Marzo y Sánchez Oñate habian servido en cuatro destinos antes, y Arnaldo, Frutos y Olóriz, en tres. El currículum de nueve de ellos se iniciaba antes la guerra y a veces incluía puestos de jurisdicción señorial (Frutos en Ollauri y las villas de Osuna, Moya en Ayamonte, Olóriz en Villar del Arzobispo y Sánchez Oñate en Menasalvas, más Juan en el Toboso, pero ya en 1815).

En llamativo contraste con lo sucedido en 1808, todos los tenientes de corregidor del Principado conservaron el puesto en 1820. El acatamiento del orden constitucional hizo que el grupo apenas experimentara cambios inmediatos:

Tabla 2: Alcaldes mayores de Cataluña en mayo de $1820^{18}$

\begin{tabular}{llclc}
\hline \multicolumn{1}{c}{ ALCALDÍA } & \multicolumn{1}{c}{ NOMBRE } & ENTRA & NATURAL & NAC. \\
\hline BALAGUER & Agustín de Velasco Calleja & 1815 Cuéllar & 1769 \\
BCN 2 & Francisco del Castillo Valero & 1815 & \\
FIGUERES & Juan Manuel Moya Fernández & 1815 Toledo & 1778 \\
GRANOLLERS & Paladio Duran de Juliá & 1815 CAMPRODON & 1774 \\
LLEIDA & José Ruiz Manzano & 1815 Granada & 1777 \\
MANRESA & Antonio Chamochín de Castro & 1815 & \\
MATARÓ & José Mariano Márquez de Aguilar & 1815 Montilla & 1762 \\
MONTBLANC & Jacinto Marzo Torres & 1815 Alhaurín & 1780 \\
TẢRREGA & Gregorio Sancho Granado & 1815 Casar & 1763 \\
VIC & Manuel Frutos & 1815 Rueda & 1771
\end{tabular}

17. Se dispone de mucha información valiosa sobre estos hombres en sus relaciones de méritos, a excepción de Castillo, Chamochín y Peláez -aunque sí sobre su hermano Juan. Además, para Sánchez Oñate, reg., y para Velasco, ACA-RA, reg. 1.414, 163 y reg. 1.416, 276, Ricardo Gómez Rivero, Los jueces del Trienio liberal, op. cit., pp. 133-134. Los cálculos para 1816 y 1808 en Autor, "La administración territorial", op. cit..

18. AHN, Consejos, legs. 13.349, 125; 13.269, 35; 13.348, 150; 13.354, 41; 13.356, 60; $13.359,34 ; 13.361,98 ; 13.363,5,28$ у $173 ; 13.371,205$ у $207 ; 13.372,53,86$ у 97; $13.375,123$ ; 13.384, 64; 13.385, 124; 13.386, 4 у $14 ; 18.53 ; 18.540 ; 18.541 ; 18.543 ; 18.544 ; 18.545$; $18.547 ; 18.552 ; 18.554 ; 18.555 ; 18.556 ; 18.557$, y $51.551,72$ y 126 . ACA-RA, reg. 1.413, 50, 390, 433, 434, 496 y 599; reg. 1.414, 23, 136, 163 y 331; reg. 1.415, 219; reg. 1.416, 214, 276, 388; reg. $1.418,17,48,188$, y reg. $1.419,86,424$ y 505. Trasladada a La Seu d'Urgell, la sede de Puigcerdà seria cubierta de forma excepcional por Armengol Dalmau de Cubells desde mayo: así se le resarcía en parte por su expulsión de la primera vara de Barcelona en 1815, cuando el Ayuntamiento la había exigido "por haber servido [Dalmau] el mismo empleo en Valencia durante el gobierno intruso" (ACA-RA, reg. 1.413, 144 y reg. 1.412, 4; AHN, Consejos, leg.13.349, 125). Sobre el caso Dalmau, ver Rafael Cerro Nargánez, "Bajo el signo de la crisis: los alcaldes mayores de Barcelona bajo el reinado de Carlos IV', Revista de Historia Moderna, $\mathrm{n}^{\circ} 28$ 2010, p. 110. Finalmente, Dalmau solicitaria a fines de enero de 1821 que se le reintegrase como juez en propiedad de Puigcerdà y La Seu d'Urgell (ACA-RA, reg. 1.419, 35). El 29 de mayo, Castellar también había nombrado a Francisco de Miguel Capdet para que ocupara provisionalmente el puesto en el Valle de Aran que su padre, Pablo de Miguel España, había dejado vacante por fallecimiento (ACA-RA, reg. 1.418, 136, y AHN-Consejos, leg. 18.539); con esa transmisión casi patrimonial, el jefe político mantenía una tradición que se remontaba a Carlos III. 


\begin{tabular}{llll} 
V.PENEDĖS & Juan Barata & 1815 MATADEPERA & 1770 \\
AGRAMUNT & Antonio Seguí Sastre & 1816 RIPOLL & 1762 \\
TARRAGONA & Manuel de Rada Martinez & 1816 Calahorra & 1767 \\
BCN 1 & Emeterio López Blanco & 1818 Nájera & 1766 \\
GIRONA & Francisco Juan Cantavella & 1818 Vistabella & 1763 \\
IGUALADA & Agustín Peláez & 1818 Piloña & 1773 \\
TORTOSA & Antonio A.Sánchez Oñate & 1818 Toledo & 1758 \\
BERGA & Salvador Arnaldo Sagarra & 1819 BELLPUIG & 1760 \\
CAMPRODON & Estanislao de Olóriz Estrelles & 1819 València & 1775 \\
\hline PUIGCERDÃ & Armengol Dalmau de Cubells & 1820 SEU D’URGELL & 1768 \\
VIELHA & Francisco de Miguel Capdet & 1820 VIELHA & \\
\hline
\end{tabular}

E1 23 de marzo de 1820, muy pocos días después de la confirmación general, el jefe político Castellar ratificó a López Blanco -que había jurado solo una semana antes- y a Castillo. Además, y ante la probable ampliación del número de juzgados en la capital, nombró como interinos a varios juristas del Principado: Rafael María Comes, José Anglasell, Bruno Ferrer y José Esteve, aunque los tres primeros dimitieron al poco ${ }^{19}$. Esto causó un nuevo nombramiento, el de José Cayetano Garcini de Salomó, a quien la Secretaría de Estado de Justicia no tardaria en dar el visto bueno ${ }^{20}$.

Que todos los alcaldes mayores de Cataluña acatasen el orden constitucional no equivale a que profesaran un liberalismo ardiente. De creer su relación de méritos, el alcalde mayor de Agramunt no solo juró la Constitución, sino que "dispuso lo hiciesen también el Ayuntamiento, corporaciones eclesiásticas y vecinos de la expresada villa", en "la plaza, y arengándoles con un discurso alegórico", pero a inicios de 1821 la Diputación aseguraría que Seguí no era contrario "al sistema constitucional, aunque tampoco decidido, sin duda por no comprender las ventajas y sabiduria de tan hermoso gobierno"21. Se habia acusado de afrancesados a Márquez de Aguilar y a Dalmau, cargo del que fueron absueltos, si bien el enésimo cambio de fidelidades que ambos consumarian en 1823 habla más bien de apego crónico al puesto ${ }^{22}$. Por si acaso, López Blanco y Ruiz Manzano pidieron a la Audiencia certificaciones de su ejercicio en los años anteriores, aunque el último manifestando su adhesión al sistema constitucional $^{23}$. El juez Francisco Juan, que juró el cargo el 3 de abril, daría en

19. ACA, RA, reg. 1.418, 130. El secretario de Estado de Justicia, Manuel García Herreros, confirmó interinamente a López Blanco y Castillo el primero de mayo y Castellar acusó recibo en nombre de la Junta dos semanas después (fols. 112 y 118). Anglasell cesó casi enseguida, el 17 de mayo, mientras que Comes y Ferrer lo harian unos días más tarde; el Gobierno admitió todas las dimisiones (fols. 121, 144, 145 y 157).

20. ACA, RA, reg. 1.418, 219.

21. AHN-Consejos, leg. 13.348, exp. 150, y Ricardo Gómez Rivero, Los jueces del Trienio liberal, op. cit., p. 43. Richard Hocquellet reparó en el gran potencial sociológico y sobre todo político de esta fuente, cuya serie más completa obra en el Archivo Histórico Nacional (en adelante AHN) (La revolución, la politica moderna y el individuo. Miradas sobre el proceso revolucionario en España (1805-1835), Prensas Universitarias de Zaragoza, Zaragoza, 2011, pp. 206-211 y 246-259).

22. Sobre Márquez, AHN-Consejos, leg. 13.361, 98.

23. ACA, RA, reg. $1.418,154$ y 160. 
los meses siguientes "pruebas repetidas de su integridad y decidido afecto al sistema constitucional" 24 .

Aun sin conocer cuál fue el sentir de los demás, debe retenerse que la restauración constitucional no halló oposición entre los jueces. No parece, en fin, que el regreso de La Pepa obedeciese solo al capricho de unos cuantos exaltados. Por supuesto, también contaba el aspecto económico, nada despreciable en tiempos tan revueltos, y cuyo monto Castellar desconocía a fines de agosto. Aunque la información que consiguió no era del todo fiable, "porque algunos solicitaron aumento y lo obtuvieron", supo que en Figueras, Vic y Granollers se venían cobrando unos 11.000 reales al año; en Barcelona, 9.400; en Manresa, 8.605; en Berga 8.378; en Balaguer, 6.453; en Mataró, 6.000; en Tàrrega, 5.866; en Agramunt, 5.817, y en Girona, Tortosa, Tarragona, Vilafranca, Puigcerdà, Lleida, Montblanc, Igualada y Camprodon, 5.37825. El Gobierno conocía la importancia de los emolumentos, por lo que al estipular la dedicación exclusiva de los jueces en agosto de 1820 repuso también la compensación de 11.000 reales anuales prevista por las Cortes en 1812.

La transición efectiva de alcaldias mayores a juzgados fue bastante lenta. E1 principal obstáculo era la delimitación de los partidos judiciales, de los que la nueva Diputación instalada en junio creía que "entre los papeles del archivo debe existir un mapa y proyecto formado por la anterior Diputación por los pertenecientes a esta Provincia, pero que según se ha insinuado es muy defectuoso"26. Los diputados comisionados para examinar la cartografia perdida la hallaron al poco, pero les pareció "muy susceptible de mejora, como se crehía [sic], y aun necesaria su reforma atendidas las muchas reclamaciones de varios pueblos"27.

Tras incorporar a dos miembros más nombrados por la Audiencia, la comisión de estudio propuso en agosto siguiente 27 partidos, agrupados en seis distritos subalternos ${ }^{28}$. Quedaron descartadas muchas poblaciones, cuyas autoridades habian reclamado una cabecera, ya basándose en precedentes

24. AHN-Consejos, leg. 13.356, 60.

25. AHDB, caja 24, 5 .

26. AHDB, Actas, 106, 4, 8 de junio de 1820.

27. Ibidem, 8, 16 de junio de 1820.

28. En el distrito de Barcelona, los partidos de Barcelona, Vilafranca del Penedès, Mataró, Granollers y Terrassa; en el de Girona, los de Girona, Figueres, La Bisbal d'Empordà, Santa Coloma de Farners y Olot; en el de Manresa, los de Manresa, Igualada, Solsona, Berga y Vic; en el de Lleida, los de Lleida, Cervera y Balaguer; en el de La Seu d'Urgell, los de La Seu d'Urgell -en lugar de Puigcerdà-, Tremp y Sort, y en el de Tarragona, los de Tarragona, Reus, Montblanc, Falset, Tortosa y Batea o Gandesa (AHDB, caja 24, 4). Eran partidos de primera clase los Barcelona (con 4 juzgados), Mataró, Tortosa, Reus, Tarragona, Lleida, Cervera, Manresa, Vic, Olot, Girona y Figueres, y de segunda, los restantes. Sobre esa propuesta de división territorial, vid. Jesús Burgueño, De la vegueria a la provincia. La formació de la divisió territorial Contemporània als Països Catalans (1790-1850), Rafael Dalmau editor, Barcelona, 1995, pp. 59-60 y 88-90. 
inmediatos, como las de Agramunt, Tàrrega, Besalú o Camprodon ${ }^{29}$, ya sin ellos, como las de Sant Joan de les Abadesses, Castelló d'Empúries,

Bayle y pueblos de la Comarca de Verges, Corregimiento de Gerona, las de los Alcaldes de San Celoni y pueblos inmediatos del Corregimiento de Mataró, la del Alcalde y Ayuntamiento de Cardona y otros pueblos de su comarca del corregimiento de Cervera, la de los particulares de Bellpuig del de Lérida y la del Ayuntamiento de Ripoll y Ripollet del Corregimiento de Vich, pretendiendo todos respectivamente que se erigiese en su Pueblo la cabeza de Partido ${ }^{30}$.

El Ayuntamiento de Talarn envió una queja -la primera de una serie que se prolongaría hasta 1834, y sin distinción de régimen- porque se había preferido a la vecina Tremp, pero la Diputación tuvo claro que esta villa

según el censo antiguo consta de doscientos vecinos y de solo ochenta y cinco la de Talarn, a lo que se añade la mayor comodidad de los pueblos de acudir a Tremp, en donde residen los empleados del ramo de aduanas y en donde llevan con más frecuencia las relaciones de comercio, y aun su misma localidad más céntrica.

Por fin, el secretario de Justicia García Herreros remitió a las Cortes el 10 de octubre de 1820 un expediente de relación de partidos de Cataluña con 25 cabeceras, las antedichas menos Sort y Batea-Gandesa. Las Cortes lo aprobaron dos semanas después, aunque quedaba pendiente la demarcación exacta de esos distritos.

\section{IMPLANTACIÓN (1821)}

Esta prudente inercia, favorable al afianzamiento del nuevo régimen, duró hasta la adjudicación de titularidades en los juzgados de primera instancia. Ricardo Gómez Rivero ha descrito en detalle un proceso donde cientos de aspirantes -entre 15 y 20 por plaza- pugnaron para entrar en las ternas de candidatos con unos interinos que, naturalmente, querian conservar el cargo y casi siempre la plaza ${ }^{31}$.

El 11 de agosto de 1820, el Consejo de Estado pidió a la Audiencia de Cataluña el preceptivo informe sobre el desempeño de los jueces existentes como paso previo a la elaboración de las candidaturas, y el 17 de noviembre, apenas un mes después de que las Cortes hubiesen aprobado las nuevas cabezas de partido, la Gaceta del Gobierno publicó la convocatoria de plazas en propiedad. No se había ultimado la división, como lo prueba que el reparto de contribuciones para el nuevo año se hubiese vuelto a formar según la antigua red ${ }^{32}$. Aun así, las ternas de Cataluña se votaron en el Consejo de Estado el 19 de enero de 1821 y todas menos una -el tercer juzgado de Barcelona- se resolvieron por unanimidad.

29. En realidad, Camprodon era sede de una alcaldia mayor, aunque el alcalde residia en Olot según costumbre. El 9 de junio, el alcalde mayor y ahora juez de primera instancia Olóriz pidió permiso para ese cambio de residencia, pero el jefe político se lo denegó (AHDB, Actas, 106, 25).

30. AHDB; caja 24, 4; también Actas, 106, 32, 3 de julio de 1820.

31. Los jueces del Trienio liberal, op. cit., pp. 20-21. Cataluña no figura entre las provincias de las que se suministran las razones de aspirantes por plaza.

32. AHDB, Actas, 105-106, 9-1-1821, 214-216. 
La publicación final de 10 de febrero de 1821 y los nombramientos subsiguientes pintaron un cuadro bastante nuevo:

Tabla 3: Jueces de primera instancia de Cataluña en $1821^{33}$.

\begin{tabular}{llll}
\hline \multicolumn{1}{c}{ ALCALDÍA } & \multicolumn{1}{c}{ NOMBRE } & \multicolumn{1}{c}{ NATURAL } & NAC. \\
\hline BALAGUER & Ramón Carvajal Trejo & Montánchez & 1782 \\
BARCELONA 1 & José Victoriano Gibert & (CATALUNA) & \\
BARCELONA 2 & J. Mariano Márquez Aguilar & Montilla & 1762 \\
BARCELONA 3 & José Esteve & (CATALUNA) & \\
BARCELONA 4 & Nicolás Malatesta Mayor & València & 1768 \\
BERGA & Blas Damián de Vega & Valladolid & 1774 \\
BISBAL D'EMPORDÀ & Juan Antonio Pérez & Areny Noguera & 1784 \\
CERVERA & Ginés María Serrano & & \\
FALSET & J. Antonio Ramos Calderón & Fregenal Sierra & 1769 \\
FIGUERES & José Porret Feliu & FIGUERES & 1783 \\
GIRONA & Fco. Juan Cantavella & Vistabella & 1763 \\
GRANOLLERS & Paladio Duran de Julià & CAMPRODON & 1774 \\
IGUALADA & Gregorio Sancho Granado & Casar & 1763 \\
LLEIDA & José Maria Aguilar Oviedo & Sevilla & 1786 \\
MANRESA & Ildefonso Gonzalo Morón & Almaluez & 1776 \\
MATARÓ & Gaspar Borràs Carbonell & BARCELONA & 1785 \\
MONTBLANC & Juan Fco. Alonso Caballero & Puente Santiago & 1771 \\
OLOT & José Vera Pantoja & Alburquerque & 1790 \\
REUS & Paulino de los Arcos & Granada & 1786 \\
Sa COLOMA FARNERS & Manuel Ma Cabrera Ruiz & Granada & 1781 \\
SEU D'URGELL & Antonio Porta Fàbregas & BARCELONA & 1790 \\
SOLSONA & Domingo Rey & Toledo & 1790 \\
TARRAGONA & Manuel de Rada Martinez & Calahorra & 1767 \\
TERRASSA & Juan Barata & MATADEPERA & 1770 \\
TORTOSA & Fco. Javier Campa Ferrer & CAMPRODON & 1759 \\
TREMP & J. Antonio Jordana de Oller & SoRT & 1765 \\
VIC & Manuel Frutos & Rueda & 1771 \\
VILAFRANCA P. & Salvador Arnaldo Segarra & BELLPUIG & 1760 \\
\hline Mantienen cargo $\boldsymbol{y}$ plaza & Mantienen cargo & &
\end{tabular}

De los 22 interinos, tan solo 5 consolidaron cargo y plaza y únicamente 3 más consiguieron otro destino en Cataluña, por extinción de la antigua sede o por traslado34; quizá se les pudiera añadir a Blas Damián de Vega, quien recobró la plaza de Berga que había ocupado hasta 1819, cuando la tuvo que abandonar por fin de sexenio. Aun así, el porcentaje de estabilizaciones no alcanza la mitad. No obstante, también lograron plaza fuera del Principado algunos jueces interinos: Chamochín (en Pamplona), Ruiz Manzano (en Córdoba), López Blanco (Estella) y Moya (Colmenar) ${ }^{35}$.

33. Ricardo Gómez Rivero, Los jueces del Trienio liberal, op. cit., pp. 66, 72-73, 127-132 y $134-$ 135, y ACA-RA, reg. 1.419, 63, 82, 84, 85, 88, 89, 91, 104, 106, 112, 124, 135 у 192; AHN, Consejos, legs. 13.366, 21; 13.374, 40, y 13.351, 22 y 106. Sobre Porret, Diccionario biográfico de parlamentarios españoles, 1820-1854, Cortes Generales, Madrid, 2013, vol. 2.

34. Sancho ocupó una plaza vacante en Tàrrega, ya que Peláez, el interino, había sido cesado por el Gobierno (ACA-RA, regs. 1.416, 214, y 1.419, 77).

35. Vid. Guía de Forasteros en Madrid para el año 1822, Imp. Nacional, Madrid, 1822, pp. 90 y 95-97. 
Las cesantias se habrian quedado en 8 de no ser porque la bailia real que ocupaba De Miguel en Aran se había extinguido y porque Sánchez Oñate siguió como interino en Tortosa un año más por ausencia del nuevo juez. También desapareció la alcaldía mayor de Agramunt, cuyo titular, Antonio Seguí, ni siquiera pudo entrar en una terna, porque "la cortedad de sus alcances, su poca instrucción, debilidad en administrar justicia y su genio demasiado bondadoso lo hacen incapaz de desempeñar con dignidad y entereza la magistratura y le han conciliado una opinión pública no muy favorable"36. Sin él, solamente Garcini, Velasco, Castillo, Olóriz y Marzo habian quedado cesantes a raíz del concurso, una quinta parte poco lesiva. El primero, que todavía ejercía como interino el 8 de abril de 1821, llegó a estar en la terna del primer juzgado de Barcelona ${ }^{37}$, y el último entró en las de Bilbao y Caravaca, sin que le valiera que la Diputación de Cataluña hubiera dicho descrito su conducta como la

más arreglada y conforme a los principios de honradez y desinterés, que deben guiar a un magistrado; que asimismo acreditó una ciencia suficiente y una particular adhesión al sistema constitucional, lo cual le había granjeado la más favorable opinión pública ${ }^{38}$.

Ninguno de los restantes figura en las guias oficiales como juez, ni siquiera interino, en otro lugar de España el resto del Trienio constitucional. Algo sabremos de ellos en las páginas finales.

Si se mira desde el ángulo opuesto, que en definitiva era el del ciudadano, se percibirá una remoción muy amplia, más aún si se la compara con la gran estabilidad de la Audiencia ${ }^{39}$. De los 28 jueces nombrados en febrero de 1821 , se estrenaban en Cataluña nada menos que 18. La media de edad de los 16 de quienes se conoce ese dato era de 42 años, lo que rebajó a 46 el promedio de todo el grupo, 5 menos que a principios de 1820. Aunque apreciable, la reducción no da para hablar de un relevo generacional, y menos cuando una parte de los nombrados tenía experiencia previa en alcaldias mayores o puestos de rango equivalente. El factor político parece haber pesado poco, pues solo consta el

36. Ricardo Gómez Rivero, Los jueces del Trienio liberal, op. cit., p. 43.

37. Solicitó a la Audiencia certificación de su ejercicio (ACA-RA, reg. 1.419, 91). Al año siguiente vendería su finca en Horta, junto a Barcelona, sin que sepamos si la venta estuvo ligada a la cesantía (Ajuntament de Barcelona, Dictricte d'Horta-Guinardó, "Torre Garcini, un nou equipament per al barri", <https://media-edg.barcelona.cat/wpcontent/uploads/2018/05/14134453/Folleto-Garcini-DinA3.pdf>, consultado el 10-1-2019).

38. Ricardo Gómez Rivero, Los jueces del Trienio liberal, op. cit., p. 43. Al parecer, Castillo se quedó fuera por votación de las ternas de Villalba del Alcor y Utrera (pp. 243-244), mientras que Velasco estuvo a punto de entrar en las de Salamanca (p. 280).

39. No hay más diferencia entre sus miembros de 1820 y 1821 que la ausencia este último año de Josef Costa y Galí, trasladado a Madrid en 1820 y muerto ese año; José María Seoane, que volvería a figurar en 1825, por lo que seguramente se ausentó por razones ideológicas, y Antonio de Asprer, asimismo realista, que cerró la lista de alguaciles mayores de aquella Audiencia (cf. Calendario manual y guía de forasteros en Madrid para el año de 1820, Imp. Real, Madrid, 1820, pp. 147-148, y Guía de forasteros en Madrid para el año de 1821, Imp. Nacional, Madrid, 1821, pp. 88-89; para Costa, Diccionario biográfico de la RAH, versión online, "Costa y Galí, José", <http://dbe.rah.es/biografias/71304/jose-costa-y-gali>, consulta 23-12-2018; para la filiación realista de Asprer, Alfonso Bullón de Mendoza, La Primera Guerra Carlista; Actas, Madrid, 1992, p. 490). 
liberalismo militante de Porret, De los Arcos, Malatesta y Borràs, el último de ellos alcalde constitucional de Mataró y vocal de la Diputación provincial de Cataluña ${ }^{40}$. En otro sentido, no por fuerza absolutista, dos de los nuevos titulares habian estado muy vinculados a los duques de Medinaceli, la casa noble más poderosa en Cataluña ${ }^{41}$ : se trata de Rey y sobre todo de Jordana, ataño procurador jurisdiccional de los duques y asesor del abad del monasterio de Gerri.

En cuanto al origen, seis de los nuevos jueces eran catalanes, un tercio exacto a medio camino entre los porcentajes de 1816 y 1820 y que se repite en el conjunto si se suman tres de los interinos ratificados. Como las ternas incluyeron una proporción alta de apellidos catalanes, cabría pensar en una aspiración de los abogados naturales del país que en parte se vio frustrada. La situación se reprodujo en Valencia, pero no en Baleares, donde la proporción de apellidos catalanes entre los nuevos jueces era del $75 \%{ }^{42}$. En sentido contrario, un vistazo a las ternas de los juzgados del resto de España muestra muy pocos apellidos catalanes, así que los puestos en la Corona de Castilla no sirvieron de compensación.

A primera vista, a los concursantes vencedores no catalanes no les había arredrado la necesidad de conocer el idioma y sobre todo el derecho del Principado, que por entonces se hallaban en plenitud de uso ${ }^{43}$. Sin embargo, algunos de esos togados no llegarian a ocupar un destino que vieron como de tránsito a otro más conveniente: aunque muchos juraron el cargo en la Audiencia entre marzo y mayo de 1821, Ramos no lo hizo, por lo que el nuevo juzgado de Falset se quedó sin inaugurar; Campa pidió permiso a la Audiencia para jurar en Castilla la Nueva, pero si lo verificó, no tomó posesión como juez de Tortosa; Arnaldo no pudo ocupar su puesto en Vilafranca, porque murió en marzo ${ }^{44}$. Carvajal no pisaría nunca el juzgado de Balaguer, pues permutó la plaza por la de Hinojosa del Duque con Miguel Calbetón Subirá, a quien tampoco se vio por las riberas del Segre; en su lugar siguió Velasco, que sería investigado por

40. Respectivamente, Alberto Gil Novales, Las sociedades patrióticas (1820-1823), Tecnos, Madrid, 1975, vol. II, pp. 766 y 919; Jordi Roca, "Politica, liberalisme i revolució a Barcelona, 1820-1823”, op. cit., p. 315, y Ricardo Gómez Rivero, Los jueces del Trienio liberal, op. cit., pp. 130131. De los Arcos se declaraba adicto desde siempre al sistema constitucional, a cuyo restablecimiento cooperó "en lo que ha estado a su alcance, por lo cual fue perseguido y procesado por la inquisición de Granada"; sin embargo, en 1822 se le acusaria de blandura con los facciosos (Ramon Arnabat, "Revolució i contrarevolució a Catalunya", op. cit., p. 946).

41. Hacia 1829 tenía como vasallos a más 125.000 almas, casi la mitad de las persones bajo jurisdicción noble en Cataluña y un octavo de la población total (vid. Autor, "Los últimos señores de Cataluña", Hispania Nova, n. 2, 2001-2002.

42. Guia... 1822, op. cit., pp. 95-96.

43. Vid. Joan Lluís Marfany, La Llengua maltractada: el català $i$ el castellà a Catalunya del segle XVI al XIX, Empúries, Barcelona, 2001, pp. 183-186 y 362-365, y Olga Fullana, "Fe de llengua. El català dels notaris catalans als inicis de l'epoca Contemporània", Ianua. Revista Philologica Romanica, $\mathrm{n}^{\circ} 17,2017$, pp. 49-60.

44. Ibidem, pp. 89-90, y ACA-RA, reg. 1.419, 41. Alonso también pidió permiso para jurar en Castilla la Nueva (ACA-RA, reg. 1.419, 87), pero se incorporó al juzgado de Montblanc. 
diversos excesos y al cabo suspendido ${ }^{45}$. Antes de que acabase el año, habria que añadir Cervera a la lista de juzgados vacíos, aunque Serrano hubiera jurado.

\section{DESPLIEGUE (1821-1822)}

La inestabilidad reinaba en la administración de Cataluña antes de que estallaran los graves conflictos interiores y exteriores que acabarian por dar fin al Trienio. Juan Munárriz fue jefe político del Principado entre febrero y junio de 1821, pero entonces le sucedió Antonio Remón Zarco del Valle, quien no tuvo nombramiento firme hasta setiembre y en febrero de 1822 volvería a ser reemplazado interinamente por Munárriz ${ }^{46}$. El mandato efectivo de Vicente Sancho como jefe político de la nueva provincia de Barcelona también fue efimero: de mayo a setiembre de 1822, cuando llenó sus funciones el intendente José Camps, a su vez reemplazado por Fernando Gómez de Butrón en noviembre 47 . Entre abril y junio de 1822 habían tomado posesión los jefes politicos de las otras provincias catalanas: el teniente coronel José Cruz de Muller en Lleida, el coronel Josef Perol en Girona y el coronel Marcelo de Baeza en Tarragona, aunque éste sería pronto sustituido por Jacobo Gil de Avalle ${ }^{48}$.

Nótese la condición militar de los nombrados, sin merma del carácter civil del cargo. Por el contrario, ese carácter iba a resultar muy útil frente al alzamiento realista que comenzó aquella primavera ${ }^{49}$. La reorganización territorial de 27 enero de 1822 había contemplado también nuevos distritos militares, de los que Cataluña pasó a ser el séptimo, y dentro de ellos, gobiernos provinciales, que se confiaron al mariscal de campo José Bellido en Lleida y a los brigadieres Esteban Llobera en Girona (junto con el gobierno de la plaza de Figueres), José María Carrillo de Albornoz en Barcelona y Miguel de Haro en Tarragona ${ }^{50}$. No obstante, y como toca a una verdadera situación bélica, el año 1823 se abrió con cambios en este escalón de mando: el brigadier Juan Antonio Aldama recibió

45. ACA-RA, reg. 1.419, 134, y Guia... 1822, op. cit., p. 89.

46. Ibidem, fols. 82,236 y 260.

47. Manel Risques, El Govern civil de Barcelona el segle XIX, op. cit., pp. 205-267. La nueva Diputación de Barcelona, presidida por el jefe político, se habia instalado el 15 de mayo de 1822 (Esteban Canales, “La Diputació a l'inici del liberalisme: 1812-1823”, en Borja de Riquer (dir.), Història de la Diputación de Barcelona, Diputació de Barcelona, Barcelona, 1987, vol. I, p. 72).

48. ACA-RA, reg. 1.420, 98 y 181; Ramon Arnabat, "Revolució i contrarevolució a Catalunya", op. cit., pp. 190-193; Antoni Simón Tarrés, La crisis del Antiguo Régimen en Girona, Universitat Autònoma de Barcelona, Bellaterra, 1985, p. 226, y Antoni Sánchez Carcelén, La revolució liberal a Lleida (1820-1823), Universitat de Lleida, Lleida, 2006, pp. 22-23.

49. Por lo demás, es anacrónico separar tajantemente lo civil y lo militar en la época de la revolución liberal o pretender que los militares fueran apolíticos entonces. Así lo revelan las alabanzas prodigadas a "nuestro anterior jefe político el ciudadano Baeza", que realizó grandes esfuerzos para poner en pie la Milicia Nacional de la provincia mientras era presidente de la Diputación tarraconense, con lo que se hizo "recomendable por su amor a la libertad constitucional" (Gaceta de Madrid, 4-8-1822, p. 1.181).

50. Ramon Arnabat, Visca el Rei i la Religió!, op. cit., p. 167. 
interinamente el gobierno de Tarragona, mientras quedaban vacantes los de Barcelona y varias plazas fuertes ${ }^{51}$.

Los juzgados de primera instancia fueron los más afectados por una provisionalidad que la rebelión realista agravó, no causó. Lo demuestra el hecho de que en mayo de 1822, antes de que el alzamiento cobrara dimensiones respetables en Cataluña y Navarra -pero casi un año después de que la Audiencia de Cataluña lo reclamara-, las Cortes autorizasen al Gobierno para que nombrase jueces interinos en lugar de los propietarios elegidos diputados a Cortes, ausentes o suspendidos de empleo y sueldo; en el interin, la responsabilidad recaería sobre los alcaldes constitucionales ${ }^{52}$.

En Cataluña, esta medida tan solo remendó una nueva planta judicial que seguía hilvanada. En diciembre de 1821, el juez Juan, de Girona, había obtenido licencia renovable por motivos de salud, y en junio de 1822 habia dimitido el juez Barata en Terrassa, lo que en la práctica trajo consigo la parálisis del juzgado vallesano ${ }^{53}$. En cambio, el juez Gutiérrez llegó a su destino de Vilafranca tras una larga ausencia, y el 14 de marzo de 1822 Manuel de Pedrolo ocupó interinamente el juzgado vacante de Cervera, aunque no consta su nombramiento ${ }^{54}$. No se puede decir lo mismo del juzgado de Olot, que Vera abandonó por el de Plasencia, ni del de Montblanc, que Alonso dejó por el de Fraga; hasta Porret prefirió la plaza valenciana de Liria a la catalana de Figueres ${ }^{55}$. También Paulino de los Arcos se fue de Reus a últimos de 1822, aunque para hacerse cargo de la jefatura politica de la provincia de Santander, y entró en su lugar el conflictivo Vega, a quien nadie reemplazó en Berga ${ }^{56}$.

Los que permanecieron tuvieron que hacer frente a unas dificultades que no por comprensibles hubieron de resultar menos frustrantes. Podía entenderse que en agosto de 1821, ante la larga enfermedad de Esteve, sus colegas de los otros juzgados del Barcelona se repartieran sus causas, pero se explica menos que el juez Jordana no tuviera ni con qué pagar el correo en Tremp y preguntara qué arbitrios se destinaban a ese y otros gastos ${ }^{57}$. Con todo, el problema principal fue desde el principio la asignación de pleitos según la nueva división de partidos,

51. Estado militar de los ejércitos de la monarquía española, Imp. Nacional, Madrid, 1823, pp. 118-119.

52. Ricardo Gómez Rivero, Los jueces del Trienio liberal, op. cit., pp. 78 y 86-87, y ACA-RA, regs. 1.419, 201, y 1.420, 158.

53. ACA-RA, reg. 1.420, 20 y 144. Una Real Orden había limitado en enero limita las licencias a ocho dias (ACA-RA, reg. 1.420, 14), pero Juan la fue renovando.

54. ACA-RA, regs. $1.419,41, \mathrm{y} 1.420,60$.

55. ACA-RA, regs. 1.419, 104, 87, 89 y 298, y 1.420, 373. Y eso que el Ayuntamiento de Figueres había informado de que la conducta de Porret "puede justamente calificarse de irreprehensible" (Ricardo Gómez Rivero, Los jueces del Trienio liberal, p. 53). En cambio, sobre Alonso pesaba la sospecha de connivencia con los realistas (Ramon Arnabat, "Revolució i contrarevolució a Catalunya", op. cit., p. 946).

56. ACA-RA, regs. $1.419,124$, y $1.421,3$ y 79.

57. ACA-RA, reg. 1.419, 202 y 110. No obstante, la Audiencia incluyó a Esteve -y a Vega- en el informe favorable emitido el 23 de diciembre de 1822 (Ricardo Gómez Rivero, Los jueces del Trienio liberal, op. cit., p. 135). 
que trajo algunos equívocos y numerosos conflictos de jurisdicción, reales o buscados. Ya en enero de 1821, el juez Peláez de Igualada se había quejado a la Audiencia de que ningún alcalde le pasaba las causas en que debía entender, y en mayo siguiente el juez Rada de Tarragona haría lo propio respecto al alcalde de Valls ${ }^{58}$. Por su parte, Gutiérrez reunía todos los problemas en Vilafranca del Penedès: no le llegaban las causas, carecía de subalternos y de fondos, y el abogado José de Martí de la Peña le había manifestado que su bufete tenía "desde tiempo inmemorial y a título oneroso" las curias de Vilanova y la Geltrú y Cubellas, que no soltaría sin indemnización ${ }^{59}$.

La presión de la guerrilla realista agudizó estas deficiencias. Tan pronto como en mayo de 1822, Jordana tuvo que trasladar el juzgado de Tremp a Sort y después huir a Francia por el peligro cierto de que los realistas invadieran la primera localidad, adonde solo volvería en marzo siguiente; en agosto de 1822, Gutiérrez tomó la decisión de mover el juzgado de Vilafranca a Vilanova i la Geltrú, porque con "la invasión de los facciosos" se habian fugado unos subalternos que le acompañarian gustosos "a punto más seguro"60. No era cosa de correr la suerte de Cabrera, el juez de Santa Coloma de Farners raptado en mayo y asesinado por la partida de mossèn Anton. La Audiencia reconoció que ese partido y los de Balaguer, Berga, Cervera, Falset, Granollers, La Bisbal d'Empordà, Montblanc, Solsona, Tremp y La Seu d'Urgell se hallaban "infestados de facciosos"61. La Secretaría de Estado de Gracia y Justicia solo aceptó el peligro el 11 de noviembre de 1822, cuando autorizó a trasladar la sede de un juzgado por riesgo de un ataque realista, y aun así el juez Pérez esperó al último día del año para huir de La Bisbal d'Empordà a Figueres ${ }^{62}$.

Así las cosas, que la Secretaría de Estado trasladase el 14 de febrero de 1823 a los titulares de Tarragona, Figueres, Gerona, Granollers y Vilafranca fuera de Cataluña y al de Solsona, Domingo Rey, a Vilafranca no hizo más que aumentar la confusión y el desánimo, apenas compensados por el nombramiento de Francisco de Paula Sagaz -presente en la terna de Lleida en 1821- para Terrassa ${ }^{63}$. Como de costumbre, Vega no estaba donde le correspondía, y así lo revela la queja elevada el 19 de febrero por el alcalde constitucional de Reus, obligado a actuar como juez interino sin asesoría alguna; Sancho también abandonaría Tàrrega a inicios de $\operatorname{marzo}^{64}$. Si a eso se le suman las ausencias y

58. ACA-RA, reg. $1.419,38$ y 120.

59. ACA-RA, reg. 1.420, 92 y 93.

60. Ibidem, fols. 157 y 261 .

61. Ramon Arnabat, Visca el Rei i la Religió!, op. cit., p. 291; una cartografia en p. 283. Cabrera había sido raptado a fines de mayo. Es comprensible que el alcalde constitucional de la villa se negara a instruir la causa contra José Baltasar Vidreras interpuesta por Salvador Llansana porque el anterior lanzó contra él a los facciosos (ACA-RA, reg. 1.421, 9).

62. ACA-RA, regs. 1.420, 373, y 1.421, 24; Ricardo Gómez Rivero, Los jueces del Trienio liberal, op. cit., p. 130. Al fin, renunciaria a la judicatura en 1823.

63. ACA-RA, reg. 1.421, 61 y 47. En balde reclamaría el Ayuntamiento constitucional de Solsona el 23 de febrero que Rey volviese de Cardona, una vez que Solsona se había fortificado y era segura (Ibidem, 66).

64. Ibidem, 3 у 70. 
evacuaciones no comunicadas, no cabrá duda de que aquella primavera el sistema judicial del Principado había llegado al colapso a pesar de la contraofensiva victoriosa de Mina.

\section{REVOCACIÓN (1823)}

Los pocos jueces que se habian mantenido frente a la rebelión realista derrotada el invierno de 1822-1823 se retiraron ante el avance de los Cien Mil Hijos de San Luis: el de Tremp se trasladó a Lleida el 23 de abril; el de Vilafranca, a Igualada el 8 de mayo; el de Montblanc, a Reus el 9 de ese mes y el de Mataró, a Barcelona el 1865. En marzo, se había instalado en el nido de águilas de Talarn un corregidor intruso que usaba papel sellado, en tanto que el gobernador militar de Aran y Castel-León, Payre, se había pasado a los realistas ${ }^{66}$. Incluso en la ciudad de Barcelona, Espoz y Mina tuvo que nombrar el 14 de agosto a dos jueces interinos: Francisco Ferrer Vilajoana -uno de los alcaldes constitucionales-y Antonio Carreny, en lugar de Esteve y de Márquez de Aguilar, el último detenido por anticonstitucional y deportado a Mallorca el 5 de setiembre de 182267.

La contrarrevolución se abatió sobre el interior del Principado siguiendo al ejército invasor. El 18 de mayo se instaló una junta corregimental en GironaFigueres, y el 3 de junio otra en Manresa, una vez que la villa hubo sido ocupada por las tropas del mariscal Moncey. Como ya había ocurrido en 1812, Manresa se convirtió en fugaz capital de Cataluña, y por eso fue alli donde el 21 de julio se constituyó una Real Audiencia por orden del comandante en jefe realista Joaquín Ibáñez-Cuevas, barón de Eroles. La regencia del tribunal recayó en José María de Cherif, y figuraron como oidores Antonio María de Bayle, Joseph Cabrera, Ramón de Lladós, Antonio Moner, Raimundo Janer y Francisco Javier de Aguiló, en tanto que Ignacio Andreu y Sans ocupó la fiscalía y Juan Daura y Cámaras, la secretaría68. Solo Cherif había pertenecido antes a la Audiencia, en concreto como oidor de la Sala del Crimen hasta $1821^{69}$.

La guerra anticonstitucional terminó el 20 de octubre de 1823, cuando Moncey y Mina cerraron un acuerdo de capitulación de Barcelona en que éste al menos consiguió que la Ciudad Condal quedase al cargo de una guarnición

65. ACA-RA, reg. 1.421, 108, 110, 113 y 119. Sobre esa nueva campaña, Ramon Arnabat, Visca el Rei i la Religió!, op. cit., pp. 405-417.

66. ACA-RA, reg. 1.421, 77, y Ramon Arnabat, "Revolució i contrarevolució a Catalunya", op. cit., p. 1.993.

67. ACA-RA, reg. 1.421, 160, y Ramon Arnabat, Visca el Rei i la Religió!, op. cit., p. 292. Corrieron la misma suerte los magistrados de la Audiencia Oñate y Castells, ambos miembros de la Sociedad del Anillo (Jordi Roca, "Politica, liberalisme i revolució a Barcelona, 1820-1823", op. cit., vol. II, p. 201).

68. ACA-RA, reg. 1.422, 1. La nueva Regencia del reino lo aprobaría el 20 de agosto (fol. 2).

69. AHN, Consejos, leg. 13.364. Andreu y Sans era hermano de José, escribano de cámara en lo civil que se convertiria en secretario interino del Real Acuerdo en 1824 y andando el tiempos ería también secretario de la Junta carlista de Berga (vid. Manuel Autor, Els Acords Reservats de la Junta de Berga, 1837-1839, Institut de Cultura de Berga, Berga, 2005, pp. 222-223)- 
francesa. Aunque ya estaba en marcha la nueva restauración absolutista, el barón de Eroles, nombrado capitán general de Cataluña en noviembre de 1823, y el marqués de Camposagrado, su sucesor en 1824, no volvieron a mandar a los corregidores de antaño, todos militares. Solo tuvieron a sus órdenes directas a cuatro nuevos gobernadores, asignados a las cabeceras de las provincias ya extintas: el teniente general conde de Penne-Villemur en Barcelona, los mariscales de campo barón de la Barre en Girona y Blas Fournás en Tarragona y el brigadier Manuel Llauder en Lleida ${ }^{70}$. Los tres primeros exhibian una acrisolada fidelidad realista y poseían una experiencia en el cargo que le faltaba a Llauder, a quien sin embargo aguardaba un brillante futuro. Con todo, Llauder y el barón de la Barre fueron pronto reemplazados. Hay que añadir al grupo al mariscal de campo Caamaño, que en rigor no fue nombrado para el mando de Figueres en febrero de 1824, sino que se le ratificó en el puesto del que había sido apartado en 1820. Caamaño -un conservador anillero pasado al realismo- y Fournás recibían el premio por haber sido apresados en Barcelona y deportados a Mallorca por orden de Mina en setiembre de $1822^{71}$.

Solo se designaron corregidores entre enero y setiembre de 1825, una vez que se hubo acelerado la purificación de la oficialidad mediante la Real Cédula de 9 de agosto de $1824^{72}$. Es significativo que no se viera la necesidad de corregidores en Vic y Vilafranca hasta 1828, tras la revuelta de los malcontents.

Tabla 4: Corregidores de Cataluña en $1825^{73}$

\begin{tabular}{lllc}
\hline CORREGIMIENTO & \multicolumn{1}{c}{ EMPLEO } & \multicolumn{1}{c}{ NOMBRE } & ENTRA \\
\hline VALLE DE ARAN & Tte. coronel & Ángel Pons & 1825 \\
CERVERA & Tte. coronel & Manuel Seco de Llanos & 1825 \\
MANRESA & Coronel & José María Bera & 1825 \\
PUIGCERDȦ & Coronel & Ignacio Simó & 1825 \\
TALARN & Coronel & José Camarlot & 1825 \\
LLEIDA & Brigadier & Luis María Andriani & 1825 \\
GIRONA & Mcal. campo & Gaspar Rocabruna & 1825 \\
MATARÓ & Mcal. campo & Juan Romagosa Pros & 1825 \\
FIGUERES & Mcal. campo & Joaquín Caamaño Pardo & $1823(1815)$ \\
TARRAGONA & Mcal. campo & Blas Fournás & 1824 \\
TORTOSA & Mcal. campo & Salvador Meléndez Bruña & 1825 \\
BARCELONA & Tte. gral. & Conde de Villemur & 1824 \\
\hline
\end{tabular}

70. AHN, Consejos, legs. 18.541, 18.545, 18.547 y 18.553. El primer nombrado para Barcelona había sido el teniente general Luis Alejandro Bassecourt de Pire, pero solo ejerció el cargo entre abril y julio de 1824 .

71. Ramon Arnabat, Visca el Rei i la Religió!, op. cit., p. 292. Sobre la filiación de Caamaño, Jordi Roca, "Política, liberalisme i revolució a Barcelona, 1820-1823", op. cit., vol. II, 201

72. José Luis Peset Reig y Mariano Peset Reig, "Legislación contra liberales en los comienzos de la década absolutista", Anuario de Historia del Derecho Español, n 37, 1967, pp. 476-479. Los autores observan con perspicacia que "el ejército se ha mostrado base de la revolución y se ha encontrado inmerso en una guerra civil", y de ahí la necesidad de una depuración especialmente cuidadosa, aunque menos rápida que en otros sectores.

73. AHN, Consejos, legs. 18.539, 18.543, 18.548, 18.550, 18.552, 18.545, 18.547 y 18.555. Camarlot había sido antiguo gobernador realista del Valle de Aran y Romagosa, jefe de la contrarrevolución en Cataluña en 1822. Sobre los estrechos vínculos de Eroles con el Pallars, vid. Autor, "Liberals $i$ absolutistes al corregiment de Talarn (1820-1840)", Ibix, n 5, 2008, pp. 338-341. 
En cuanto a los jueces de primera instancia, el absolutismo triunfante hizo tabla rasa de ellos antes y con mayor contundencia que con los uniformados. A fin de cuentas, la represión requería fusiles, aunque no fueran del todo fiables. En la administración, en cambio, se aplicó una purga en toda regla -la primera en la historia contemporánea de España-, pasando por encima de derechos y ejecutorias y sin más base legal que la victoria armada ${ }^{74}$.

En virtud de la orden de la Regencia de 12 de junio de 1823, se exoneró a todos los jueces de primera instancia y en su lugar se impuso un elenco de alcaldes mayores tan nuevo que desmentía toda voluntad restauradora. Se podría establecer un nexo con el anterior período absolutista en la persona de Agustín Peláez, el juez de Igualada a quien el Gobierno liberal había destituido en 1821, de no ser porque el absolutista también lo haría en $1825^{75}$. Velasco, juez de Balaguer hasta 1821, fue destinado a Granollers en mayo de 1823, pero cesó solo dos meses después ${ }^{76}$. Chamochín, que había conseguido plaza en Pamplona en el concurso de 1821, volvió a la que había ocupado en Manresa, pero fue impurificado y la perdió ${ }^{77}$. Solo López Blanco, que había conseguido la plaza de Estella en 1821, recuperó la de Barcelona, aunque trasfalta ganar un recurso ante la Audiencia ${ }^{78}$.

Merecen mención aparte las vicisitudes de Dalmau de Cubells, quien tras muchos pleitos había logrado que se le diera el juzgado de La Seu d'Urgell en mayo de 1820, no había ganado plaza en el concurso de 1821 y en agosto de 1824 recibió Vilafranca del Penedès gracias a una confesión de absolutismo con alguna que otra inexactitud:

Durante el llamado gobierno constitucional no obtuvo destino alguno de aquel gobierno revolucionario [?], antes por el contrario ha sido perseguido por él y llevado públicamente con fuerza armada a la ciudadela de Barcelona, exigiéndole por su constante amor y decidida adhesión al Rey nuestro Señor la multa de mil duros, la que tuvo que aprontar para conseguir su libertad; pero viendo que aquel gobierno continuaba persiguiéndole, abandonó su casa y familia, y con mucho riesgo se fugó de Barcelona ${ }^{79}$.

Dos jueces que habian sacado plaza en Cataluña en el concurso de 1821 iban a ser alcaldes mayores durante la década absolutista de 1823-1833 gracias al transformismo politico: el anillero Márquez de Aguilar, deportado en setiembre de 1822, llegó a corregidor de letra en Alcaraz en 1825, mientras que Malatesta,

74. José Luis Peset Reig y Mariano Peset Reig, "Legislación contra liberales...", op. cit., pp. 439444, y Regina Polo, "El régimen local entre el absolutismo y el liberalismo", p. 750.

75. ACA-RA, reg. 1.416, 214.

76. ACA-RA, reg. 1.423, 161 y 264.

77. ACA-RA, regs. 1.423, 384; 1.424, 505, y 1.425, 263.

78. ACA-RA, reg. 1.423, 284.

79. AHN, Consejos, leg. 13.349, 125, y ACA-RA, reg. 1.424, 78. A Dalmau, que había comenzado su carrera aspirando a una canongia en Àger sin tener la edad necesaria, las mentiras siempre le fueron rentables, como demuestra que en febrero de 1825 fuera ascendido a alcalde del crimen de la Audiencia. 
su colega en Barcelona que pasaba por exaltado, se alzó con la alcaldia mayor de Agramunt en octubre de aquel año gracias a una rápida conversión 80 .

Se había nombrado a muchos interinos durante la ofensiva francesa y hasta mediados de 182481. Ahora bien, el nuevo régimen había dictado las depuraciones para que "los negocios del Reino no recayeran en personas que abusaran de sus empleos", y ante el peligro opuesto de un alud de oportunistas, la maquinaria depuradora se detuvo un tiempo, entre octubre y diciembre de 1823. Esa pausa y el mayor cuidado posterior en la selección explican que tan solo Abad y Jordana retuvieran sus plazas en Cataluña y que los demás interinos fueran sustituidos por otros con mejor currículum, al menos en lo profesional. Vale la pena leer la profesión de fe realista de Comajuncosa, comandante provisional de una compañia de Voluntarios Realistas nada menos que en Talarn $\mathrm{y}$

Que lejos de ser notado de adicto al sistema constitucional, que ha odiado, se ha adquirido un concepto muy singular de serlo a la Soberanía del Rey nuestro Señor y a su legítimo y paternal Gobierno; que por esta razón y por su acreditado desempeño y probidad, en el mes de Setiembre del año mil ochocientos veinte y dos fue nombrado individuo de una Junta llamada de opiniones políticas de Talarn, que de orden de la Superior de Urgel se creó para formar espedientes contra las personas notadas de constitucionales, lo que le atrajo de la parte de estos y de su inicuo gobierno una persecución terrible que le tuvo mucho tiempo en prisión con centinelas de vista, y formación de proceso militar como a enemigo de aquel sistema revolucionario, y de lo cual hubiera sido víctima, si poco antes de ser juzgado militarmente en Consejo de guerra no se hubiera fugado y evadido de su poder.

Por su parte, Manuel Valonga Zaidín, pariente directo del barón de Eroles y hermano del brigadier Benito Valonga,

Durante el gobierno constitucional se manifestó desde un principio tan amante del Rey nuestro Señor como opuesto a la constitución y resoluciones de las Cortes, cuya oposición le atrajo la malevolencia de los adictos a aquel sistema, sus persecuciones, padecimientos y perjuicios ${ }^{82}$.

A falta de unos nombramientos para Aran y Tortosa que no llegarian hasta 1828, se percibe un aumento de la proporción de naturales del Principado respecto a la fase anterior: 8 sobre 20 nombrados en propiedad, un $40 \%$ algo

80. Calendario manual y guia de forasteros en Madrid para el año de 1826, Imp. Real, Madrid, 1826, p. 129, y AHN, Consejos, leg. 18.543. Sobre las posiciones politicas de ambos en el Trienio, Jordi Roca , "Política, liberalisme i revolució a Barcelona, 1820-1823", op. cit., pp. 201 y 531. El escurridizo Blas Damián de Vega solo sería comisionado excepcionalmente para ejercer de alcalde mayor de Igualada entre diciembre de 1825 y abril de 1826 (ACA-RA, reg. 1.425, 161 y 183).

81. A Manuel Juan Abad Escudero para Agramunt; a José Antonio Balcells para Balaguer; primero a Paladio Duran de Julià, después a Lorenzo Collell y de nuevo a Figueroa para las tenencias de Barcelona; a Felipe Vilamala para Figueres; a Fermín Gigó para Lleida; a Ildefonso Figueroa para Mataró; sucesivamente a Antonio Girabancas, Matías Mestre, y Odón Macià de Llopart para la problemática tenencia de Montblanc; a Leopoldo Jordana de Eril para Puigcerdà; a Jaime Guillén para Talarn; a Pedro Ribera Rius y más tarde a Antonio Queralt para Tàrrega, y a Buenaventura Fortuny Marfany -que ya lo había sido en Granollers en 1810, como regidor decano- para Vic (AHN, Consejos, leg. 18.543; ACA-RA, regs. 1.421, 50 y 100; 1.422, 2; 1.423, $264,318,289,293$, y $1.424,86$ y 90.

82. AHN, Consejos, leg. 18.553, y ACA-RA, reg. 1.424, 90, 295, 297 y 389. La tenencia de Mataró era ejercida interinamente desde julio por Benito Estraban (ACA-RA, reg. 1.423, 264). 
superior al de 1816, pero que se elevaría al $50 \%$ si se incluyese a los dos originarios de la localidad aragonesa, fronteriza y catalanoparlante de Tamarit de Llitera.

Tabla 5: Alcaldes mayores de Cataluña a mediados de $1825^{83}$.

\begin{tabular}{llclc}
\hline \multicolumn{1}{c}{ ALCALDÍA } & \multicolumn{1}{c}{ NOMBRE } & ENTRA & \multicolumn{1}{c}{ NATURAL } & NAC. \\
\hline AGRAMUNT & Manuel Abad Escudero & 1823 & Brihuega & 1798 \\
IGUALADA & Agustín Peláez & 1823 & Piloña & 1773 \\
PUIGCERDÀ & Leopoldo Jordana de Eril & 1823 & CASTELLÀs & 1780 \\
BALAGUER & Ramon Vilaplana & 1824 & SOLSONA & 1772 \\
BARCELONA 1 & Vicente Diaz Ruesgas & 1824 & Palencia & 1787 \\
BARCELONA 2 & Emeterio López Blanco & 1824 & Nájera & 1766 \\
BERGA & Marcos Ant ${ }^{\circ}$ Comajuncosa & 1824 & (CATALUÑ) & \\
CAMPRODON & Juan Carrera Carrera & 1824 & BANYOLES & 1789 \\
FIGUERES & Francisco Casas de Galí & 1824 & TARRAGONA & \\
GIRONA & Miguel de los Santos Puig & 1824 & (CATALUÑA) & \\
GRANOLLERS & José Matías Cabrera Purroy & 1824 & Tamarit Ll. & 1779 \\
MANRESA & Benito Bonet & 1824 & Monteagudo & 1794 \\
MONTBLANC & Andrés Masegosa Soriano & 1824 & Molina S. & 1796 \\
TÁRREGA & Ramón Bernús & 1824 & (CATALUÑA) & \\
VIC & Manuel Berbiela & 1824 & Jaca & 1788 \\
VILAFRANCA P. & Armengol Dalmau de Cubells & 1824 & SEU D’URGELL & 1768 \\
LLEIDA & Félix Cuende Vallejo & 1825 & Madrid & 1787 \\
MATARÓ & José Català Cruañes & 1825 & Xàbia & 1773 \\
TALARN & Manuel Valonga Zaidín & 1825 & Tamarit Ll. & 1771 \\
TARRAGONA & Pedro Hernáiz de Segura & 1825 & Valdelaguna & 1769 \\
\hline
\end{tabular}

Como había ocurrido al final de la Guerra Peninsular, la proporción es mucho más alta en los interinos, de los que se cuentan 8 catalanes por 2 no catalanes. Queda fuera de duda un arraigo del realismo en Cataluña que se vería corroborado los lustros siguientes. También está clara la entrada de sangre nueva que la depuración trajo consigo, ya que la edad promedio de los titulares descendió hasta los 44,6 años, en buena parte porque tres de ellos estaban por debajo de la treintena en 1824.

Al igual que en el ámbito militar, es revelador que no se completara el cuadro judicial, y eso que no debieron de faltar pretendientes. O bien se creyó que en las alcaldías mayores no provistas bastaba con el corregidor -aunque las autoridades locales de Cervera llevaran décadas pidiendo lo contrario- o bien se entendió que no se podía rehacer el viejo sistema tal cual. Además, la reposición

83. AHN, Consejos, legs. 13.348 (174), 18.540, 18.541, 18.544, 18.545, 18.548, 18.552, 18.554 y 18.556; ACA-RA, reg. 1.423, 264, 284, 369 y 378. Con todo, Vilaplana y Carrera conocieron una breve interinidad (ACA-RA, reg. 1.423, fol. 264). Balcells se quejó de su cese en el 28 de julio de 1824 (Ibidem, fol. 295). Díaz Ruesgas también exhibía un brillante expediente como realista: "notoriamente desafecto al sistema" constitucional, y por ello cesado como juez, "preso y conducido con fuerza militar a la ciudad de Murcia por complicado en la causa de conspiración contra el sistema" en setiembre de 1820, pasó a Orihuela e junio 1821 y fue acusado de conspiración en 1822 (AHN, Consejos, leg. 13.380, 75). Cabe suponer el origen catalán de Puig y Bernús; los datos ciertos provienen de AHN, Consejos, legs. 13.348, 174; 13.349, 125; 13.351, 83; $13.356,40,91135$ у 136; 13.357, 38; 13.364, 16, 24, 52 у 147; 13.370, 60 у 112; 13.372, 12, 57,63 у 89; 13.373, 13; 13.374, 40; 13.375, 96 у 123; 13.377, 67; 13.380, 75; 13.385, 124, у 13.386, 1 . 
automática de los titulares a inicios de 1820 que pedia la orden de la Regencia habría lesionado los intereses de quienes hubieran conseguido traslados favorables en 1820 o 1821, con independencia de su toma de partido posterior.

Aun así, hubo margen para premiar a algunos agraviados reales o supuestos, siempre y cuando acreditaran su militancia absolutista. Entre quienes habian quedado cesantes por el concurso de 1821, Olóriz se proclamó "sugeto de buena vida y costumbres [...] que ha dado pruebas positivas de amor a la Religión y a la Monarquía" y por ello logró una subdelegación de rentas en febrero de 1823 y más adelante una tenencia de corregidor en Murcia ${ }^{84}$. Castillo Valero fue designado oidor de la sala del crimen de la Audiencia de Extremadura en 182485. Por fin, hay que incluir en este rubro a algunos descartados de las ternas de 1821 , en primer lugar a Bonet, que no había logrado su objetivo en Barcelona con 26 años y el bachillerato en leyes recién sacado, pero lo consiguió en Manresa con apenas $30 \mathrm{y}$ tras abstenerse de pertenecer "a sociedad alguna pública ni secreta de las reprobadas por las leyes, antes por el contrario se ha conservado fiel a la justa causa del rey nuestro Señor"86. Cuende había sido eliminado para Mataró y ahora lograba plaza fija en Lleida. En cambio, Macià de Llopart, que había entrado en la terna de Cervera, se quedó con una simple interinidad en Montblanc, un puesto tan poco deseable que otro eliminado, Mestre, prefirió irse a Fraga.

\section{ALGUNAS CONCLUSIONES}

Se da por supuesto que los años transcurridos entre el colapso del absolutismo borbónico y la implantación del Estado liberal fueron un tiempo estéril, de avances y retrocesos vanos, pero al analizar los cambios que se produjeron en los niveles inferiores del poder se perciben los reajustes y las transacciones con la realidad social y politica que también caracterizaron a esa dificil etapa. Pese a la enorme distancia ideológica y doctrinal entre realistas y liberales, por debajo del ruido, el odio y las venganzas, se puede seguir un hilo de conducta que obedeció a la necesidad de adaptarse a un tiempo nuevo.

El régimen constitucional que resurgió en 1820 también estuvo marcado desde el principio por la contradicción entre unos objetivos revolucionarios y la praxis reformista a que obligaban las circunstancias. Esa tensión fue patente en Cataluña, donde se localizaría el principal foco militar y político de la contrarrevolución en 1822-1823. Así, el antiguo Principado se convirtió en uno de los principales teatros de la pugna entre el esquema legal de la monarquía absoluta y el del liberalismo, y tanto por su carácter fronterizo como por la amplitud y variedad de sus conflictos internos. Así había quedado demostrado en 1808-1814 y así lo revelarían las luchas de 1822-1823, 1827-1828 y 1833-1840.

84. AHN, Consejos, legs. 13.354, 41, y 13.269, 35, Calendario manual y guia de forasteros en Madrid para el año de 1825, Imp. Real, Madrid, 1825, p. 140).

85. Calendario...1825, op. cit., p. 123.

86. AHN, Consejos, leg. 13.351, 83. 
Las autoridades que aplicaban en Cataluña la justicia de Fernando VII como rey absoluto, alcaldes mayores y miembros de la Real Audiencia, habian aceptado más o menos gustosas el regreso de la Carta Magna. El Gobierno respondió a la anuencia con una confirmación general que trajo algunos meses de paz y aparente afianzamiento, pero el concurso de provisión de plazas para los nuevos juzgados de primera instancia de febrero de 1821 liquidó la conciliación. Los criterios ideológicos no fueron decisivos en unas adjudicaciones que se saldaron con pocas cesantías, aunque la naturaleza misma del proceso frustró las expectativas de muchos aspirantes y su larga duración generó inseguridad en los antiguos titulares.

Este no fue el único error de los liberales en su afán de instaurar un diseño previo, por legitimo y adecuado que fuera: también cometieron el muy común de acometer una reforma sin medios En Cataluña, donde los juzgados de primera instancia funcionaban por primera vez, hubo desde el principio abundantes faltas de coordinación entre autoridades y una clara escasez de recursos, sobre todo en las localidades que no habian sido sedes antes. En ese contexto, la rebelión realista que comenzó en la primavera de 1822 produjo efectos devastadores sobre la planta judicial en ciernes, y la posterior victoria sobre la contrarrevolución no dio respiro bastante para que se solventaran los problemas.

Hizo falta la invasión de los Cien Mil Hijos de San Luis para que el absolutismo consiguiera lo que no habia logrado con sus propias fuerzas. Como en el resto de España, la contrarrevolución derribó en Cataluña todo lo edificado en el Trienio, incluidos los juzgados de primera instancia y los gobiernos militares, y en su lugar resucitó las alcaldías mayores y los corregimientos, que volvían a unir lo judicial y lo administrativo. A diferencia de 1814 y de 1821 , quienes ocuparon esos puestos tuvieron que acreditar su militancia realista y superar unas depuraciones que habian comenzado incluso antes de que Fernando VII volviera a reinar como monarca absoluto. A la mayoría de quienes habian ostentado esos cargos en el periodo constitucional les esperaba el cese y el ostracismo, cuando no el exilio o la cárcel.

Sin embargo, el retorno a 1819 era imposible por más represión que se aplicase, y lo sabian los realistas en el doble sentido de la palabra. La gradualidad en el retorno de los corregidores y la prolongación de las vacantes en algunos corregimientos y alcaldías mayores ofrecen buenos indicios de ello. Los cambios en el Ejército dictados por el marqués de Zambrano desde 1825 y la creación de nuevas alcaldias mayores en Cataluña en 1828 iban a confirmar muy pronto la necesidad de reformas.

Fecha de envio / Sumission date: 12/02/2019

Fecha de aceptación / Acceptance date: 22/04/2019 